\title{
Heart Failure Prediction in
}

\section{Athletic Heart Remodeling among Long Distance Runners}

\author{
Hossam Abdel Aleem Shaheen ${ }^{1 *}$, Manal Ahmed Mohamed ${ }^{2}$, Fatma Hasan Abdel Basset ${ }^{3}$, \\ Mostafa Hamed Rashed1, Neethu Betty Theruvan', Soad A. Mosbah'1
}

\author{
${ }^{1}$ Department of Cardiac Technology, College of Applied Medical Sciences, Imam Abdulrahman Bin Faisal University, Dammam \\ City, Kingdom of Saudi Arabia \\ ${ }^{2}$ Department of Biochemistry, National Heart Institute, Giza, Egypt \\ ${ }^{3}$ Department of Physical Sport, Sohar University, Sohar, Oman \\ Email: `hashaheen@iau.edu.sa,mhrashed@iau.edu.sa,emadfawzy@hotmail.com, \\ fbaset@su.edu.om,nbtheruvan@iau.edu.sa,samosbah@iau.edu.sa
}

How to cite this paper: Shaheen, H.A.A., Mohamed, M.A., Basset, F.H.A., Rashed, M.H., Theruvan, N.B. and Mosbah, S.A. (2022) Heart Failure Prediction in Athletic Heart Remodeling among Long Distance Runners. World Journal of Cardiovascular Diseases, 12, 1-10.

https://doi.org/10.4236/wjcd.2022.121001

Received: November 8, 2021

Accepted: January 9, 2022

Published: January 12, 2022

Copyright $\odot 2022$ by author(s) and Scientific Research Publishing Inc. This work is licensed under the Creative Commons Attribution International License (CC BY 4.0).

http://creativecommons.org/licenses/by/4.0/

\begin{abstract}
Background: Physical activity has a cardinal role in preventing and treating cardiovascular diseases. Understanding the changes that occur to the cardiac muscle in athletes is still doubtful whether it is only an adaptation to exercise or a concealed pathological condition. Most of these changes are well documented in apparently healthy heart and characterized by cardiac enlargement with Brady-arrhythmias specially individuals participating in long distance runners with exercise capacity without signs of cardiovascular disease. Methods: The study searched the subclinical myocardial necrosis by comparing two groups of young marathon runners, both groups were chosen from $\mathrm{Al}$ Gizera youth center in January 2018. First group included adults above the age of 18 years and ran for $12 \mathrm{~km}$. and the second was under 18 years and ran for about $8 \mathrm{~km}$. Both groups were volunteered for this study. They are monitored carefully with blood pressure, heart rate and respiratory rate and their blood samples were collected pre- and post-race immediately for assessment of cardiac markers NTproBNP, Galectin-3 and cTnI. Results: All cardiac markers were elevated post exercise compared to that achieved in pre-exercise regardless age of athletes. Also, pre-exercise adult results were higher in galectin-3 and cTnI but not in proBNP while there is no difference in the acute response in both groups. These results revealed micro cardiac necrosis due to long run exercise with possible bad prognosis. Conclusions: It is important to develop risk assessment and prediction methods for screening the young athletes and consider the term athletic heart as a subclinical disorder rather than physiological adaptation.
\end{abstract}




\section{Keywords}

Athletes, Exercise, Phidippides Cardiomyopathy, Remodeling

\section{Introduction}

The documented health benefits of regular exercise are well known and established. This makes participation in exercises like long run marathons (more than 10,000 meters), continues to gain popularity all over the world due to its strength, physical and reactional competition. During exercise, there is a physiological direct relationship between the intensity (work out) and the body's demand for oxygen. This increasing requirement of oxygen is corrected by increasing lung uptake of oxygen with subsequently increasing in pulmonary oxygen uptake $\left(\mathrm{VO}_{2}\right)$. The increased cardiac output $(\mathrm{CO})$ expressed in (liters per minute) is responsible for transporting oxygen-rich blood from the lungs to the skeletal muscles [1].

Early investigations in 1899 by Henschen and skidwettlauf documented cardiac enlargement and brady arrhythmias in individuals with above-normal exercise capacity without attendant signs of cardiovascular disease [2]. Since that time, the investigators with the help of cardiovascular diagnostic imaging develops the term athletic heart in order to understand the association between sport participation and specific cardiac abnormalities. The athletic heart phenomenon is well established and explained by that repetitive participation in vigorous physical exercise results in significant changes in myocardial structure (especially cardiac Mass) and function. Recent increases in the popularity of recreational exercise and competitive athletics have led to a growing number of individuals exhibiting this phenomenon [3].

The story of athletic heart is still arguable, there is an ongoing debate about the true nature of the athlete's heart, whether it is only a physiological adaptation explained by conditioning process or a potentially hidden pathological condition. The reports about elevated cardiac biomarkers after prolonged endurance exercise [4]. The ECG abnormalities are common in trained athletes and have been attributed to the physiologic cardiac adaptations and an elevated vagal tone which mainly controls the heart during rest and explains the bradycardia that occurs because of regular physical exercise. The incidence of these ECG patterns linked with gender, ethnicity and depends on the sporting discipline, intensity and level of training [5].

Phidippides cardiomyopathy also is another well defined phenomenon in endurance athletes. It is developed because of sustained increase in cardiac output for several hours with subsequentially increase in volume overload and its impact on the myocardium walls. Dilatation of the right atrium and ventricle was noticed in approximately one-third of marathon runners, also elevations of natriuretic peptides and cardiac troponin. With follow up of those groups of ath- 
letes, a smaller fraction developed small patches of cardiac fibrosis that act as substrate for ventricular tachyarrhythmias and sudden death [6].

Age, gender, ethnicity and sporting discipline have an important impact on the magnitude of cardiac remodeling. Looking for racial factor, Black athletes exhibit striking abnormalities and left ventricular hypertrophy (LVH) which may be regarded as an ethnic variant of the athlete's heart [7].

Competitive sports are thought to be a trigger rather than a cause for lifethreatening arrhythmias in athletes with underlying cardiovascular diseases. A total of $14.4 \%$ of athletes showed distinct abnormalities, most commonly in cyclists, followed by cross country skiers and tennis players [8]. Compared to Caucasian athletes, ECG abnormalities and especially deep T wave inversions are more common in black athletes [9] [10] [11].

Early studies considered athletic heart as a pathological change due to strenuous training and thereby leads to progressive deterioration in function. The hallmark findings are chamber enlargement and ventricular hypertrophy with electrocardiographic abnormalities including increased voltage criteria, abnormal Q waves, and T-wave inversions [1] [12]. Currently, sport Medicine clinicians, practicing the term athletic heart as a physiological increase in cardiac mass with circulatory and morphological adaptation to athletic training. This evidence is supported by the concept that this represents adaptive physiology, not preclinical disease [12].

The challenge remains in differentiating athlete's heart from some types of cardiac disease. Despite the considerable advances in diagnostic tests, ECG and morphological changes found in athletes can mimic findings of some types cardiomyopathies like, hypertrophic cardiomyopathy (HCM), dilated cardiomyopathy, arrhythmogenic right ventricular cardiomyopathy (ARVC), and other cardiovascular diseases. The absence of a definitive diagnostic test or gold standard test for many cardiovascular commonly results in diagnostic uncertainty [13] [14]. All these investigations depend upon heart dimensions and ECG or echocardiography findings but there are no biochemical markers used for prediction of the ongoing prognosis of this enlarged heart [14].

Recently, there are many markers associated with immuno-inflammatory and neurohormonal responses to heart damage have been identified. Among immunity and inflammatory markers, Neurohormones include Brain Natriuretic peptides derivatives (ProBNP), Cardiac injury (necrosis, apoptosis) markers including Cardiac troponins (cTnI and $\mathrm{cTnT}$ ) and Matrix remodeling, endothelial dysfunction, and inflammatory markers including Galectin 3 share the ability to define the severity of the ongoing ventricular remodeling process [15].

The aim of this study is to investigate and compare between adults older than 18 years old long-distance runners and young aged long-distance runners using the biochemical heart failure markers including ProBNP (Brain Natriuretic Peptides), cTnI (Cardiac Troponin I), and Galectin-3 in order to detect subclinical myocardial injury. 


\section{Material and Methods}

\subsection{Subjects}

This is a Cohort study designed to compare between two randomly selected groups. Written informed consent was taken, demographic, clinical and laboratory data were collected. First group consisted of eight adult elite athletes completed cross country running experiment held in Al Gizera youth center on Friday 12 , January 2018 . They completed a $12 \mathrm{~km}$ running. Their age were $24.7 \pm$ 1.2 years, weight $68.5 \pm 1.9 \mathrm{~kg}$ and height $174.3 \pm 8.2 \mathrm{~cm}$. The second group was eight subjects from the same experiment, but their age was under 18 years and ran for eight $\mathrm{km}$. according to the protocol and ethics introduced by the Egyptian Federation of track and field events. Their ages were $17.7 \pm 0.8$ years, weight $62.4 \pm 2.2 \mathrm{~kg}$ and height $165.9 \pm 3.6 \mathrm{~cm}$. All subjects are voluntarily participants.

Exclusion criteria of this study are: no clinical or analytical evidence for any disease among the study groups.

\subsection{Blood Analysis}

Blood samples at rest were collected under aseptic conditions from the anti-cubital vein. Post-exercise blood sampling was performed immediately after the exercise. Samples were collected in tubes containing coagulation activator in resting for at least 30 minutes and immediately after exercise, centrifuged and kept at $-20^{\circ} \mathrm{C}$ until tested. ProBNP, cTnI, and Galectin 3 levels were determined using a commercial ELISA kit provided by Teco medical group, Germany.

\subsection{Statistical Analysis}

All data are reported as mean \pm standard deviation (SD). The SPSS 19 software computer program was used to execute all statistical analyses. The nonparametric two related sample test ( $\mathrm{Z}$ test) was used to compare the means of each group before and after the training program. All the data were correlated to exercise. The level of significance was set at $\mathrm{p} \leq 0.05$.

\section{Results}

Table 1 summarizes results of the adult group pre and post exercise including the cardiac necrosis markers. Results revealed significant difference in all parameters investigated.

Table 1. Results of adult group at pre-exercise compared to post-exercise.

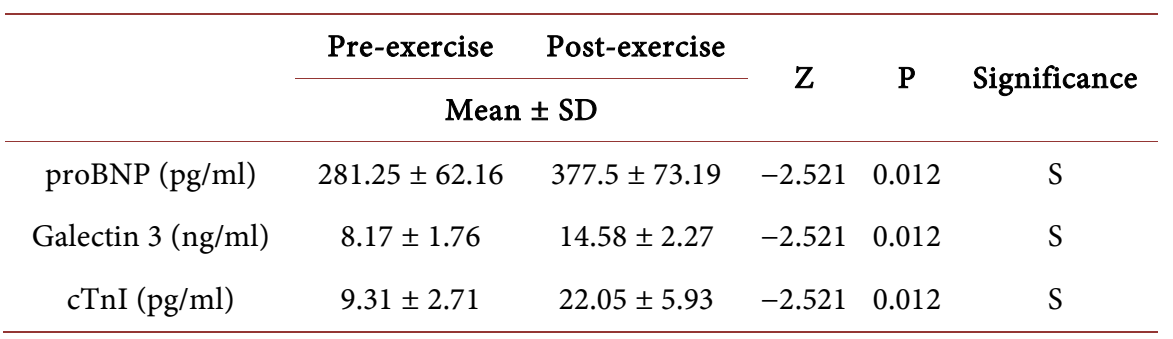


Table 2 revealed the same findings resulted in the adult group for under 18 years' group. All investigated parameters were also significant with higher levels post-exercise.

Table 2. Results of under 18 years group at rest compared to after exercise.

\begin{tabular}{|c|c|c|c|c|c|}
\hline & Pre-exercise & Post-exercise & \multirow{2}{*}{$\mathrm{Z}$} & \multirow{2}{*}{$\mathbf{P}$} & \multirow{2}{*}{ Significant } \\
\hline & \multicolumn{2}{|c|}{ Mean \pm SD } & & & \\
\hline $\operatorname{proBNP}(\mathrm{pg} / \mathrm{ml})$ & $271 \pm 57.79$ & $336.25 \pm 43.85$ & -2.380 & 0.017 & $S$ \\
\hline Galectin $3(\mathrm{ng} / \mathrm{ml})$ & $6.82 \pm 0.91$ & $12.512 \pm 2.02$ & -2.521 & 0.012 & $S$ \\
\hline cTnI (pg/ml) & $7.27 \pm 1.79$ & $18.56 \pm 3.92$ & -2.521 & 0.012 & $S$ \\
\hline
\end{tabular}

When the two groups are compared at pre-exercise (Table 3), result revealed significant high levels in adult group in galectin 3 and cardiac troponin I (cTnI) but no differences in N-terminal pro-brain natriuretic peptide (proBNP) levels.

Table 3. Results of adult group compared to under 18 years at rest (pre-exercise).

\begin{tabular}{cccccc}
\hline & \multicolumn{2}{c}{ Mean \pm SD } & Z & P & Significant \\
\cline { 2 - 5 } & Adult & Under 18 years & & & \\
\hline proBNP $(\mathrm{pg} / \mathrm{ml})$ & $281.25 \pm 62.16$ & $271 \pm 57.79$ & -0.420 & 0.674 & $\mathrm{NS}$ \\
Galectin 3 $(\mathrm{ng} / \mathrm{ml})$ & $8.17 \pm 1.76$ & $6.82 \pm 0.91$ & -2.100 & 0.036 & $\mathrm{~S}$ \\
cTnI $(\mathrm{pg} / \mathrm{ml})$ & $9.31 \pm 2.71$ & $7.27 \pm 1.79$ & -1.960 & 0.050 & $\mathrm{~S}$ \\
\hline
\end{tabular}

The most important results were postulated in Table 4 which revealed no differences in response to exercise in both groups. There are elevated post-exercise levels in all three cardiac parameters regardless to age.

Table 4. Results of adult group compared to under 18 years post-exercise.

\begin{tabular}{ccccccc}
\hline & \multicolumn{2}{c}{ Mean \pm SD } & & \multirow{2}{*}{ Z } & P & Significant \\
\cline { 2 - 5 } & Adult & Under 18 years & & & \\
\hline proBNP $(\mathrm{pg} / \mathrm{ml})$ & $377.5 \pm 73.19$ & $336.25 \pm 43.85$ & -1.540 & 0.123 & NS \\
Galectin 3 $(\mathrm{ng} / \mathrm{ml})$ & $14.58 \pm 2.27$ & $12.512 \pm 2.02$ & -1.540 & 0.123 & NS \\
cTnI $(\mathrm{pg} / \mathrm{ml})$ & $22.05 \pm 5.93$ & $18.56 \pm 3.92$ & -1.540 & 0.123 & NS \\
\hline
\end{tabular}

There is a positive correlation between exercise and proBNP $(r=909, \mathrm{p}<$ $0.001)$ and between proBNP and $\mathrm{CTnI}(\mathrm{r}=732, \mathrm{p}<0.04)$ in adult group. In under 18 years group, the correlation was found between galectin 3 and proBNP either before or after exercise. 


\section{Discussion}

The risk of myocardial damage by endurance exercise is under debate because of reports on exercise-associated increases in cardiac biomarkers and myocardial dysfunction (Haykowsky et al., 2018). Aim of this study was to investigate athletic heart phenomenon presented in many athletes especially who participated in long heavy endurance sports like long distance and marathon runners [16].

There are many sports can lead to athletic heart with suspected developed heart failure including Badminton, Cross-country skiing, Field hockey, Orienteering, Race walking, Racquetball, Squash, Running (long distance) and Soccer [17].

All cardiac parameters were elevated post-exercise compared with pre-exercise levels. These results indicated at least minor cardiac necrosis due to heavy exercise sessions. Moreover, rest cardiac markers' levels in adult were higher than that observed in younger athletes (under 18 years) indicating chronic effect of such sports with the recurrent participation in.

Release of cardiac biomarkers was observed in a previous study by Fortescue et al. (2007), the injured myocardium released a trace of myoglobin, cardiac troponin-I, creatine kinase, and creatine kinase myocardial band, and B-type natriuretic peptide. Another study by McCullough et al. (2011) noticed, volume depletion with reduced renal filtration occurs with elevated blood urea nitrogen, serum creatinine, and cystatin C [18] [19].

Pelliccia et al., 2010 suggested that increases in cardiac troponins are only mild in athletes and of short duration and, therefore, may reflect a reversible membrane leakage or breakdown of the cell membrane of cardiac myocytes with subsequent troponin release from the free cytosolic pool [20].

Hättasch et al. (2013) found that pre-exercise serum levels of galectin-3 were higher in long distance runners than control active non-athletic groups. The serum levels of galectin-3 were higher in endurance athletes and increased significantly from base line in pre-exercise to peak in post-exercise samples $(12.8 \pm 3.4$ $\mathrm{ng} / \mathrm{mL}$ to $19.9 \pm 3.9 \mathrm{ng} / \mathrm{mL}, \mathrm{p}<0.001)$. They concluded that Plasma galectin-3 is substantially elevated in endurance athletes, both after short-term abstinence and especially after running. The galectin-3 levels do not correlate with cardiac function or other biomarkers. galectin- 3 increase during endurance exercise may originates primarily from skeletal muscle [21].

NT-proBNP concentrations under resting conditions are not elevated in healthy athletes with or without signs of the athlete's heart. Short term elevations of NT-proBNP after prolonged exercise may have cyto-protective and growthregulating effects on the athlete's heart [22] [23]. However, studies on persistent RV dysfunction in highly trained endurance athletes with ventricular arrhythmias suggest that elevated cardiac biomarkers may reflect an exercise-induced myocardial injury to the RV [23] [24].

Post-marathon (Boston marathon 2006) cardiac biomarkers were elevated in at least $40 \%$ of participants especially cardiac Troponin T levels. The NT-proBNP increased significantly after the race. There was a significant correlation between 
elevated cardiac biomarkers and post-race diastolic dysfunction, significant increase in pulmonary bed pressures, right ventricular dysfunction.

Regarding the training mileages and marathon runners, athletes with the lowest training mileages exhibited the highest risk for myocardial injury and dysfunction [24]. At least one-third of individuals after a marathon, irrespective of baseline factors, speed, or conditioning, will have a rise and fall of cardiac troponin and B-type natriuretic peptide [25].

La Gerche et al. (2008) postulated that the theory of heart remodeling is applicable when the myocardium faces an increased pressures or volume overload for long times. It responds by changing its shape, the left ventricular chamber size, thickness, and mass indices are increased [26]. Running for long distances especially in a competition initiates a catecholamine surge with subsequent cardiac injury, due to coronary vasoconstriction and increased heart rate that will lead to decrease in diastolic filling time of the coronary arteries, increased demand for oxygen, changes in free fatty acid metabolism, lactic acidosis, and metabolic derangements [27]. As a result, the heart is unable to keep up with the demands of running and increasing right heart preload and afterload and begins to dilate and stretch in response to these hemodynamic changes [28]. These changes may be more pronounced in those with less training [29].

Right heart dilation and hypokinesis after prolonged strenuous exercise has been observed using cardiac magnetic resonance imaging [30] [31]. Diastolic dysfunction is frequently observed in both younger and older athletes [32]. After one-month follow-up of marathon race, systolic function of the LV and RV returned to normal, while LV and RV diastolic function were still abnormal. However, to date there are no reports of a higher incidence of heart failure in athletes [29].

During the recovery period after long distance run, the cardiac geometric dimensions are restored, and many athletes continue this cycle with training, running, cardiac disturbances, and again cardiac recovery. With this repetitive stretch of the chambers and restoration of the chamber geometry, we believe there are individuals prone to developing chronic structural changes, including chamber dilation and myocardial fibrosis, as a response to the repetitive volume overload and dynamic strain of the heart [33] [34].

In conclusion, it is unclear whether long distance runners' group, in particular, will go on to develop patches of cardiac fibrosis. These changes are asymptomatic and probably occur over many years. However, in those who experience ventricular arrhythmias and/or sudden cardiac death there is this lethal disorder, Phidippides cardiomyopathy. Thus, it is rational to develop risk prediction and screening methods for this disorder to allow counseling for individuals who are considering endurance sports such as cross country and marathon running.

\section{Acknowledgements}

The authors extend their sincere appreciation to Dr. Emad Fawzy, MD, Clinical pathology for helping and advising us throughout this work and his help to get 
the analytical results.

\section{Conflicts of Interest}

The authors declare no conflicts of interest regarding the publication of this paper.

\section{References}

[1] Baggish, A.L. and Wood, M.J. (2011) Athlete's Heart and Cardiovascular Care of the Athlete: Scientific and Clinical Update. Circulation, 123, 2723-2735. https://doi.org/10.1161/CIRCULATIONAHA.110.981571

[2] Bohm, P., Scharhag, J. and Meyer, T. (2016) Data from a Nationwide Registry on Sports-Related Sudden Cardiac Deaths in Germany. European Journal of Preventive Cardiology, 23, 649-656. https://doi.org/10.1177/2047487315594087

[3] De Innocentiis, C., Ricci, F., Khanji, M.Y., Aung, N., Tana, C., Verrengia, E., Petersen, S.E. and Gallina, S. (2018) Athlete's Heart: Diagnostic Challenges and Future Perspectives. Sports Medicine, 48, 2463-2477. https://doi.org/10.1007/s40279-018-0985-2

[4] Kooreman, Z., ve Giraldeau, G., Finocchiaro, G., Kobayashi, Y., Wheeler, M., Perez, M., Moneghetti, K., Oxborough, D., George, K.P., Myers, J., Euan Ashley, E., and Franc, F. (2018) Athletic Remodeling in Female College Athletes: The "Morganroth Hypothesis” Revisited. Clinical Journal of Sport Medicine, 29, 224-231.

[5] Sharma, S., Drezner, J.A., Baggish, A., Papadakis, M., Wilson, M.G., Prutkin, J.M., et al. (2017) International Recommendations for Electrocardiographic Interpretation in Athletes. Journal of the American College of Cardiology, 69, 1057-1075. https://doi.org/10.1016/j.jacc.2017.01.015

[6] Trivax, J.E. and McCullough, P.A. (2012) Phidippides Cardiomyopathy: A Review and Case Illustration. Clinical Cardiology, 35, 69-73. https://doi.org/10.1002/clc.20994

[7] Kato, T.S., Noda, A., Izawa, H., Yamada, A., Obata, K., Nagata, K., Iwase, M., Murohara, T. and Yokota, M. (2004) Discrimination of Nonobstructive Hypertrophic Cardiomyopathy from Hypertensive Left Ventricular Hypertrophy on the Basis of Strain Rate Imaging by Tissue Doppler Ultrasonography. Circulation, 110, 3808-3814. https://doi.org/10.1161/01.CIR.0000150334.69355.00

[8] Risgaard, B., Winkel, B.G., Jabbari, R., et al. (2014) Sports-Related Sudden Cardiac Death in a Competitive and a Noncompetitive Athlete Population Aged 12 to 49 Years: Data from an Unselected Nationwide Study in Denmark. Heart Rhythm, 11, 1673-1681. https://doi.org/10.1016/j.hrthm.2014.05.026

[9] Di Bello, V., Talini, E., Dell'Omo, G., et al. (2010) Early Left Ventricular Mechanics Abnormalities in Prehypertension: A Two-Dimensional Strain Echocardiography Study. American Journal of Hypertension, 23, 405-412. https://doi.org/10.1038/ajh.2009.258

[10] Breuckmann, F., Möhlenkamp, S., Nassenstein, K., et al. (2009) Myocardial Late Gadolinium Enhancement: Prevalence, Pattern, and Prognostic Relevance in Marathon Runners. Radiology, 251, 50-57. https://doi.org/10.1148/radiol.2511081118

[11] Karjalainen, J., Kujala, U.M., Kaprio, J., Sarna, S. and Viitasalo, M. (1998) Lone Atrial Fibrillation in Vigorously Exercising Middle Aged Men: Case-Control Study. British Medical Journal, 316, 1784-1785. https://doi.org/10.1136/bmj.316.7147.1784

[12] Scharhag, J., Weins, F., Urhausen, A., et al. (2008) Volume vs. Intensity in the Training of Competitive Swimmers. International Journal of Sports Medicine, 29, 
906-912. https://doi.org/10.1055/s-2008-1038377

[13] Heidbuchel, H., Hoogsteen, J., Fagard, R., Vanhees, L., Ector, H., Willems, R., et al. (2003) High Prevalence of Right Ventricular Involvement in Endurance Athletes with Ventricular Arrhythmias. Role of an Electrophysiologic Study in Risk Stratification. European Heart Journal, 24, 1473-1480.

https://doi.org/10.1016/S0195-668X(03)00282-3

[14] Ector, J., Ganame, J., van der Merwe, N., Adriaenssens, B., Pison, L., Willems, R., et al. (2007) Reduced Right Ventricular Ejection Fraction in Endurance Athletes Presenting with Ventricular Arrhythmias: A Quantitative Angiographic Assessment. European Heart Journal, 28, 345-353. https://doi.org/10.1093/eurheartj/ehl468

[15] Rudolph, A., Abdel-Aty, H., Bohl, S., et al. (2009) Noninvasive Detection of Fibrosis Applying Contrast-Enhanced Cardiac Magnetic Resonance in Different Forms of Left Ventricular Hypertrophy Relation to Remodeling. Journal of the American College of Cardiology, 53, 284-291. https://doi.org/10.1016/j.jacc.2008.08.064

[16] Haykowsky, M.J., Samuel, T.J., Nelson, M.D. and La Gerche, A. (2018) Athlete's Heart: Is the Morganroth Hypothesis Obsolete? Heart, Lung and Circulation, 27, 1037-1041. https://doi.org/10.1016/j.hlc.2018.04.289

[17] Perseghin, G., De Cobelli, F., Esposito, A., Alberti G., et al. (2007) Effect of the Sporting Discipline on the Right and Left Ventricular Morphology and Function of Elite Male Track Runners: A Magnetic Resonance Imaging and Phosphorus 31 Spectroscopy Study. American Heart Journal, 154, 937-942.

https://doi.org/10.1016/j.ahj.2007.06.039

[18] Fortescue, E.B., Shin, A.Y., Greenes, D.S., et al. (2007) Cardiac Troponin Increases among Runners in the Boston Marathon. Annals of Emergency Medicine, 49, 137-143.E1. https://doi.org/10.1016/j.annemergmed.2006.09.024

[19] McCullough, P.A., Chinnaiyan, K.M., Gallagher, M.J., et al. (2011) Changes in Renal Markers and Acute Kidney Injury after Marathon Running. Nephrology, 16, 194-199. https://doi.org/10.1111/j.1440-1797.2010.01354.x

[20] Pelliccia, A., Kinoshita, N., Pisicchio, C., Quattrini, F., Dipaolo, F.M., Ciardo, R., et al. (2010) Long-Term Clinical Consequences of Intense, Uninterrupted Endurance Training in Olympic Athletes. Journal of the American College of Cardiology, 55, 1619-1625. https://doi.org/10.1016/j.jacc.2009.10.068

[21] Hättasch, R., Spethmann, S., de Boer, R.A., et al. (2014) Galectin-3 Increase in Endurance Athletes. European Journal of Preventive Cardiology, 21, 1192-1199.

[22] Goodman, J., Thomas, S. and Burr, J.F. (2013) Cardiovascular Risks of Physical Activity in Apparently Healthy Individuals Risk Evaluation for Exercise Clearance and Prescription. Canadian Family Physician, 59, 46-49.

[23] Krip, B., Gledhill, N., Jamnik, V., et al. (1997) Effect of Alterations in Blood Volume on Cardiac Function during Maximal Exercise. Medicine \& Science in Sports \& EXercise, 29, 1469-1476. https://doi.org/10.1097/00005768-199711000-00013

[24] Neilan, T.G., Yoerger, D.M., Douglas, P.S., Marshall, J.E., Halpern, E.F., Lawlor, D., et al. (2006) Persistent and Reversible Cardiac Dysfunction among Amateur Marathon Runners. European Heart Journal, 27, 1079-1084.

https://doi.org/10.1093/eurheartj/ehi813

[25] Baggish, A.L., Wang, F., Weiner, R.B., et al. (2008) Training-Specific Changes in Cardiac Structure and Function: A Prospective and Longitudinal Assessment of Competitive Athletes. Journal of Applied Physiology, 104, 1121-1128. https://doi.org/10.1152/japplphysiol.01170.2007

[26] La Gerche, A., Connelly, K.A. and Mooney, D.J. (2008) Biochemical and Functional 
Abnormalities of Left and Right Ventricular Function after Ultra-Endurance Exercise. Heart, 94, 860-866. https://doi.org/10.1136/hrt.2006.101063

[27] Trivax, J.E., Franklin, B.A., Goldstein, J.A., et al. (2010) Acute Cardiac Effects of Marathon Running. Journal of Applied Physiology, 108, 1148-1153.

https://doi.org/10.1152/japplphysiol.01151.2009

[28] Gaasch, W.H. and Zile, M.R. (2011) Left Ventricular Structural Remodeling in Health and Disease: With Special Emphasis on Volume, Mass, and Geometry. Journal of the American College of Cardiology, 58, 1733-1740. https://doi.org/10.1016/j.jacc.2011.07.022

[29] Knebel, F., Schimke, I., Schroeckh, S., et al. (2009) Myocardial Function in Older Male Amateur Marathon Runners: Assessment by Tissue Doppler Echocardiography, Speckle Tracking, and Cardiac Biomarkers. Journal of the American Society of Echocardiography, 22, 803-809. https://doi.org/10.1016/j.echo.2009.04.009

[30] Mousavi, N., Czarneck, A., Kumar, K., et al. (2009) Relation of Biomarkers and Cardiac Magnetic Resonance Imaging after Marathon Running. American Journal of Cardiology, 103, 1467-1472.

[31] Gerche, A., Burns, A.T., Mooney, D.J., et al. (2012) Exercise-Induced Right Ventricular Dysfunction and Structural Remodelling in Endurance Athletes. European Heart Journal, 33, 998-1006. https://doi.org/10.1093/eurheartj/ehr397

[32] Cameli, M., Lisi, M., et al. (2013) Left Ventricular Remodelling and Torsion Dynamics in Hypertensive Patients. The International Journal of Cardiovascular Imaging, 29, 79-86.

[33] Pelliccia, A., Maron, B.J., De Luca, R., et al. (2002) Remodelling of Left Ventricular Hypertrophy in Elite Athletes after Long-Term Deconditioning. Circulation, 105, 944-949. https://doi.org/10.1161/hc0802.104534

[34] D’Silva, A. and Papadakis, M. (2015) Sudden Cardiac Death in Athletes. European Cardiology Review, 10, 48-53. https://doi.org/10.15420/ecr.2015.10.01.48 